\title{
In Vitro Studies of the Blood-Brain Barrier Using Isolated Brain Capillaries and Cultured Endothelial Cells ${ }^{a}$
}

\author{
GARY W. GOLDSTEIN, A. LORRIS BETZ, AND \\ PHILLIP D. BOWMAN \\ Departments of Pediatrics and Neurology \\ University of Michigan \\ Ann Arbor, Michigan
}

KATERINA DOROVINI-ZIS

University of British Columbia

Vancouver, British Columbia

The formation of the blood-brain barrier is dependent upon several special properties of the endothelial cells in brain capillaries. To learn more about the cellular events involved in control of blood-brain barrier permeability, our research group developed methods to prepare suspensions of highly purified microvessels from brain tissue ${ }^{1}$ and to grow the endothelial cells in primary cell culture. ${ }^{2,3}$ These two in vitro preparations have proved useful in defining cellular characteristics of the brain capillary that cannot be easily investigated in vivo. Several recent reviews concerning use of these preparations are available. ${ }^{4-6}$ In this manuscript, work carried out in our laboratory is presented to illustrate the use of in vitro preparations to study the blood-brain barrier.

The tight junctions that continuously seal together the endothelial cells in brain capillaries are probably the single most important anatomic feature underlying the formation of the blood-brain barrier. Isolated brain microvessels provide a concentrated source of these junctions that permit both morphologic and biochemical analysis. Preservation of these junctional complexes in vitro is illustrated in FigurE 1, a transmission electron photomicrograph of an isolated brain microvessel in cross section. The tight junction is seen joining two of the endothelial cells together. When isolated brain capillaries are examined by freeze-fracture analysis (FIG. 2), the complexity of the endothelial cell tight junction becomes apparent. ${ }^{7}$ Multiple interconnecting grooves and ridges indicate the "very tight" nature of the junctional complexes.

\footnotetext{
${ }^{a}$ Supported by Grant ES-02380 from the National Institutes of Health. A. L. B. is the recipient of an Established Investigatorship from the American Heart Association. K. D.-Z. was supported by a Teacher Investigator Award (1K07NS00708) from the National Institutes of Health.
} 

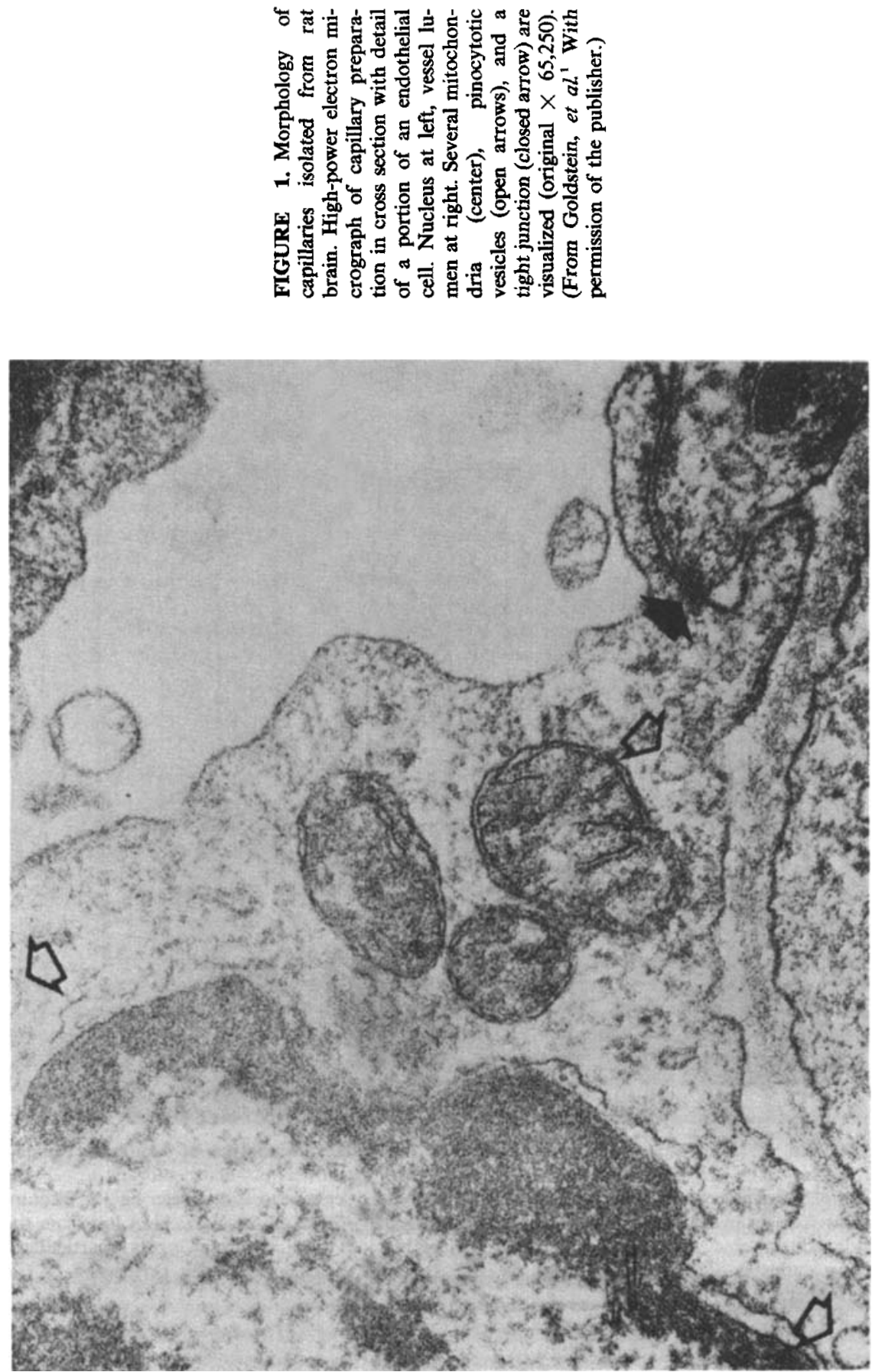


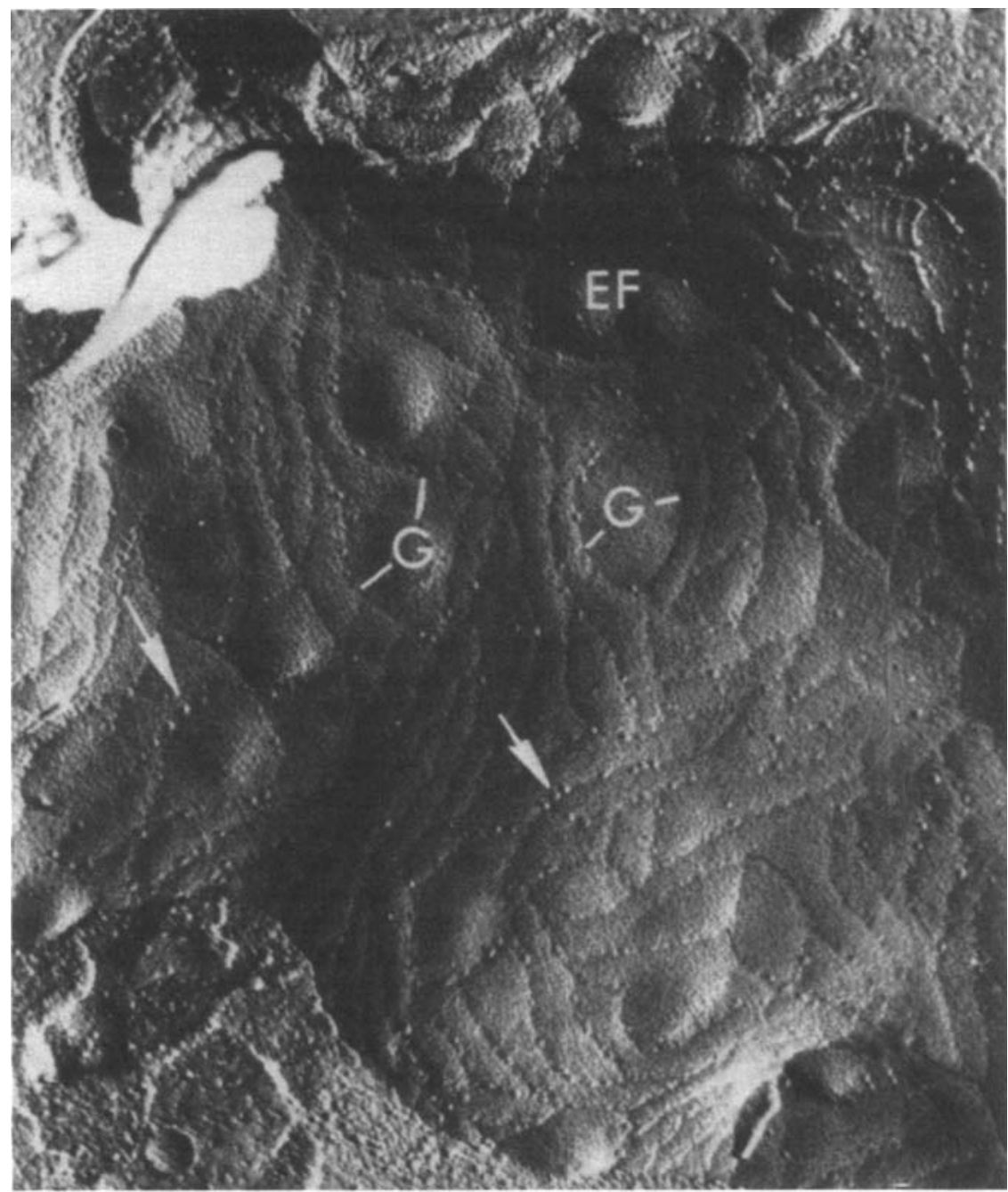

FIGURE 2. Morphology of a tight junction by freeze-fracture analysis of capillaries isolated from rat brain. The EF fracture face (EF) of capillary endothelia plasma membrane reveals the complex system of intramembrane grooves $(G)$ complementary to ridges seen on PF fracture faces. The grooves possess some intramembrane particles (arrows) that have been lost from the ridges during cleavage. The high degree of interlock between the junctional elements is particularly conspicuous in this micrograph $(\times 54,000)$. (From Shivers et al. ${ }^{7}$ With permission of the publisher.) 
This pattern is similar to the structure of tight junctions in relatively impermeable epithelia ${ }^{8}$ but differs from the discontinuous particle arrays seen in junctional complexes in nonbarrier capillaries such as those in the choroid plexus. This finding is consistent with the very low permeability of sodium and potassium across the luminal face of the blood-brain barrier as well as with physiologic studies indicating a high electrical resistance of the brain capillary wall.'

In addition to creating a permeability barrier across the capillary wall, the tight junctions between the endothelial cells may provide in part the basis for segregating plasma membrane proteins between the luminal and abluminal surfaces of the endothelium. We believe that certain transport carriers in brain capillaries are asymmetrically distributed between the luminal and the brain surfaces. ${ }^{10,11}$ Thus, $\mathrm{Na}^{+} \mathrm{K}^{+}$. ATPase, the Na-dependent $\mathrm{A}$-system amino-acid transporter, and a $\mathrm{Na}^{+}-\mathrm{H}^{+}$antiport all seem to be predominantly located on the abluminal surface of the brain capillary, while the amiloride-sensitive $\mathrm{Na}^{+}$channel and furosemide-sensitive $\mathrm{NaCl}$ transporter are located primarily on the luminal surface. ${ }^{12}$

FIGURE 3 illustrates this polar distribution of transport systems. The reaction product of $\mathrm{K}^{+}$-stimulated phosphatase activity was found predominantly on the abluminal surface of the brain capillary. This enzyme represents the sodium-potassium pump, and its abluminal location should permit the endothelial cell to participate in regulation of potassium concentration in the interstitial fluid. In conjunction with a luminal sodium channel, this ion pump may also be responsible for secretion of fluid into the interstitial space. Transporters for D-glucose, large neutral amino acids, and other essential substrates are probably symmetrically present on both surfaces of the capillary wall. This polar model of the brain capillary is illustrated in schematic form in Figure 4. Not shown in the schematic are the receptors for prostaglandins, catecholamines, and peptides now known to be present on brain capillaries. ${ }^{13}$ The effect of these potential regulators of capillary function on the control of microvascular perfusion and permeability have not yet been determined.

Suspensions of isolated brain microvessels present several limitations for investigating brain capillary function-they are viable for only a few hours, substrates are presented primarily to the abluminal surface of the capillary and transport studies consist of uptake and release by cells in suspension rather than through a cellular layer. To overcome these limitations, we and others developed methods to grow brain capillary endothelial cells in tissue culture. The cells are identified by their characteristic morphology and the presence of Factor VIII/von Willebrand antigen, which is found almost exclusively in endothelium (FIG. 5A, B). In primary culture, the cells form a continuous monolayer without intercellular gaps. When examined by scanning (FIG. 5C) and transmission electron microscopy (FIG. 5D), small overlapping membranes are seen that are similar to the marginal folds found on the luminal aspect of capillaries in vivo. Freeze-fracture analysis of the cultured cells (FIG. 5E) reveals characteristic tight junctional complexes, although the junctions in culture do not appear as complex as the ones found in freshly isolated microvessels (Fig. 2).

When a monolayer of the brain capillary endothelial cells is incubated with media containing horseradish peroxidase (HRP), no reaction product was found within the junctional complex or beneath the cell layer. ${ }^{14}$ Only an occasional pinocytotic vesicle became filled with reaction product. In this regard, the monolayer closely resembled in vivo preparations that use horseradish peroxidase to document the ability of the blood-brain barrier to restrict the passage of proteins across the capillary wall. After the monolayer was exposed to hyperosmotic solutions of arabinose for several minutes, the horseradish peroxidase readily penetrated the junctional complexes and accumulated beneath the cell layer (FIG. 6). Almost all of the junctions contained HRP after five minutes of exposure to $1.6 M$ arabinose, the same concentration used to 
open the blood-brain barrier in vivo. ${ }^{15}$ Despite the marked alteration in junction permeability, we found no change in the number of pinocytotic vesicles filled with reaction product. Our in vitro observation thus provides further evidence that an enhanced permeability after exposure of brain capillaries to hyperosmotic solutions is due to separation of tight junctions rather than activation of pinocytosis.

It is possible to grow monolayers of brain capillary endothelial cells on a permeable support matrix to study transcellular permeability. Using cells grown on collagen-

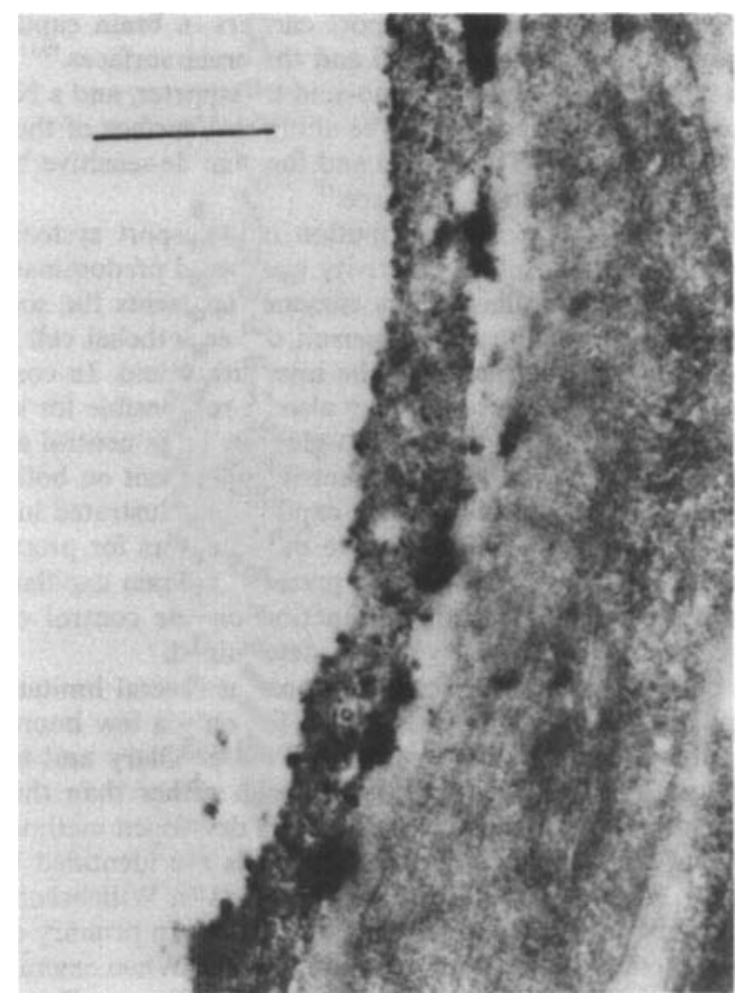

FIGURE 3. Cytochemical localization of $\mathrm{Na}^{+}, \mathrm{K}^{+}$-ATPase in a brain capillary endothelial cell. The incubation mixture contained L-tetramisole and $10 \mathrm{mM} \mathrm{K} \mathrm{K}^{+}$. Electron-dense reaction product is present only on the antiluminal membrane of the endothelial cell. Bar represents $0.25 \mu \mathrm{m}$. (From Betz et $a l^{10}$ With permission of the publisher.)

coated nylon mesh, we found that the rate of $\left[{ }^{14} \mathrm{C}\right]$ sucrose movement across the endothelial cell monolayer increased $40 \%$ after exposure of the cells to hyperosmotic arabinose. ${ }^{3}$ A more dramatic separation of the endothelial cells occurred when they were briefly incubated in a calcium-free buffer. With this latter treatment, sucrose permeability increased $120 \%$ over control monolayers. Using a similar chamber, Beck et al. studied the effect of coculture of endothelial cells with glial cells and found evidence for assymetrical transport of a small neutral amino-acid (A-system) analogue. ${ }^{16}$ 


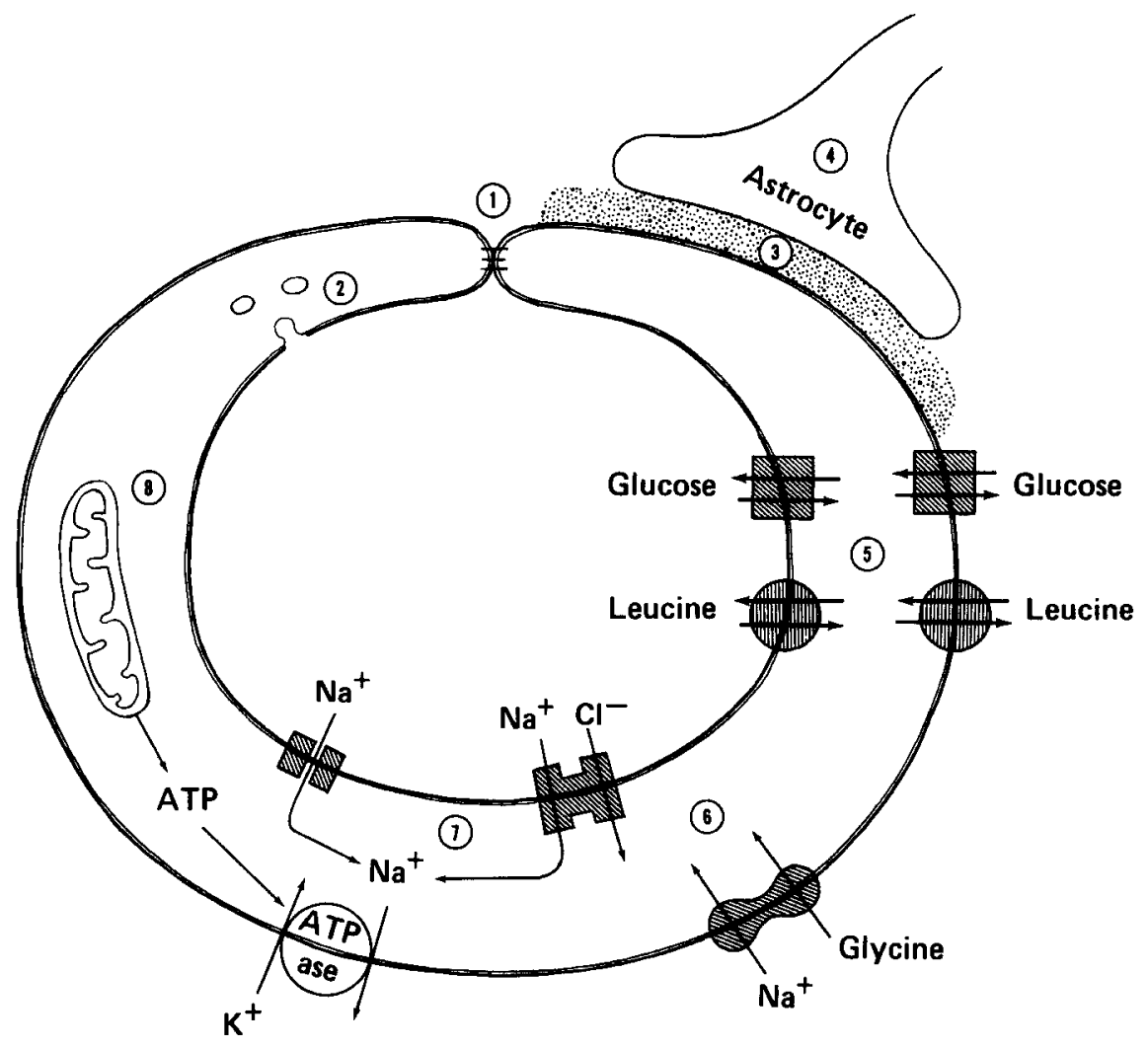

FIGURE 4. Model of brain capillary. The tight junctions (1) that join endothelial cells together in brain capillaries are continuous and complex, and they limit the diffusion of large and small solutes. Very few pinocytotic vesicles (2) are found in the cytoplasm, and this potential route for transendothelial transport is not operative in normal brain capillaries. The basement membrane (3) provides structural support for the capillary and may influence endothelial cell function. Foot processes of astrocytes (4) encircle the capillary but do not create a permeability barrier. Transport carriers (5) for glucose and essential amino acids facilitate the movement of these solutes into brain. Active transport systems (6) appear to cause efflux of certain small amino acids from brain to blood. $\mathrm{Na}^{+}$pores and $\mathrm{NaCl}$ carriers on the luminal surface of the endothelial cell and $\mathrm{Na}^{+}, \mathrm{K}^{+}$-ATPase on the antiluminal surface account for ion movements across the brain capillary (7). Mitochondria (8) produce the ATP needed for energy-dependent transport processes. Not shown are receptor sites for agents that may regulate the permeability of this barrier. (From Goldstein and Betz. ${ }^{17}$ With permission of the publisher.) 

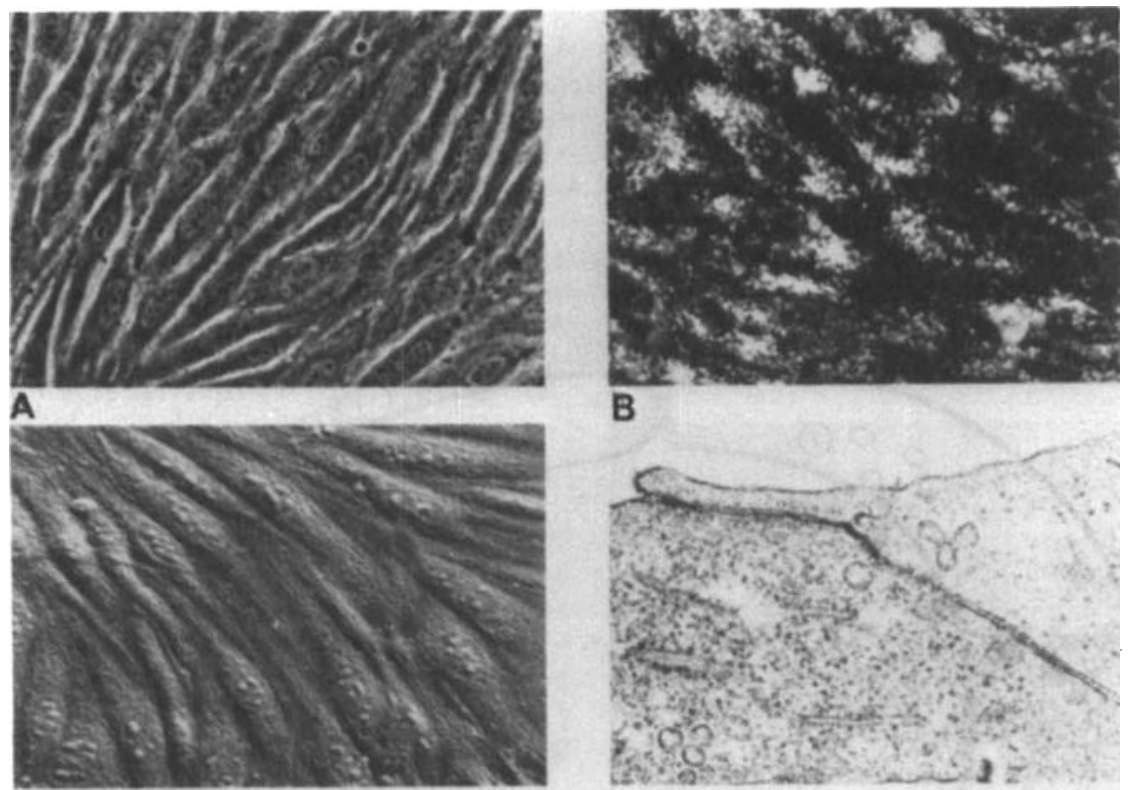

B

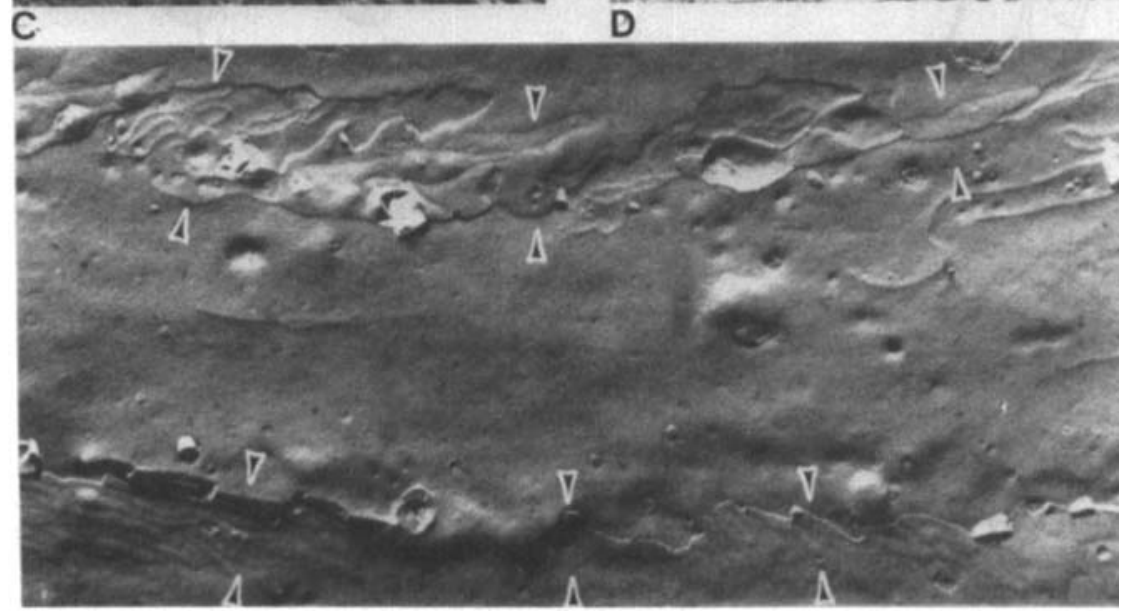

E

FIGURE 5. Characteristics of cultured brain microvessel endothelial cells. (A) Phase contrast micrograph of confluent bovine brain endothelial cells. ( $\times 525$ before $10 \%$ reduction.) (B) Immunofluorescent demonstration of factor VIII/von Willebrand antigen in cultured bovine brain microvessel endothelial cells ( $\times 1,200$ before $10 \%$ reduction). (C) Scanning electron micrograph of cultured bovine brain microvessel endothelial cells, demonstrating close apposition of cells ( $\times 700$ before $5 \%$ reduction). (D) Transmission electron micrograph of cultured bovine brain microvessel endothelial cells, revealing overlap and a junctional complex between two cells. Only a few pinocytotic vesices are visible ( $\times 41,000$ before $10 \%$ reduction). (E) Transmission electron of platinum-carbon replica of freeze-fractured endothelial monolayer. Arrows demarcate the borders of tight junctions between cells. Complex anastomosing linear arrays of membrane particles are apparent. ( $\times 35,000$ before $5 \%$ reduction). (From Bowman et al. ${ }^{3}$ With permission of the publisher.) 


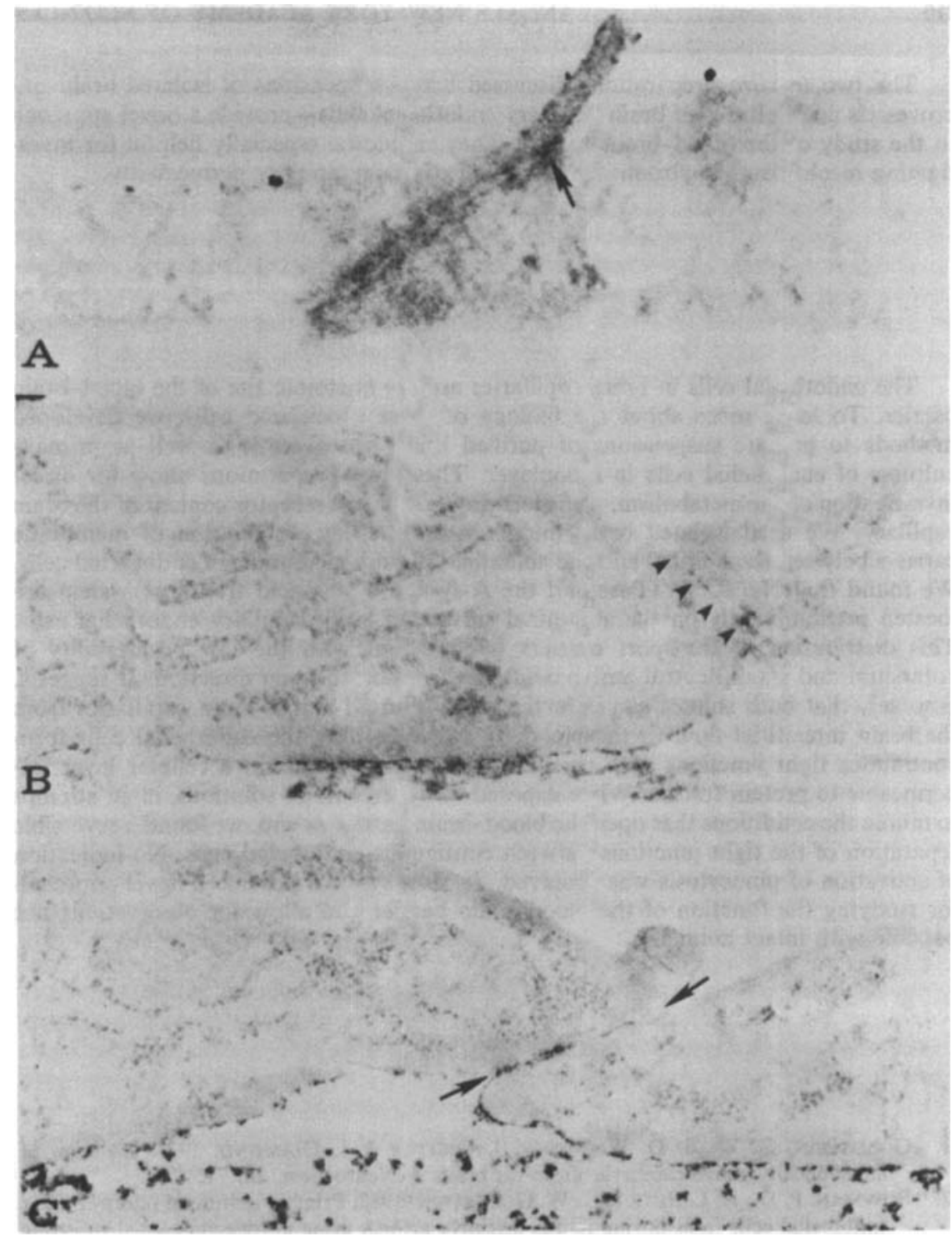

FIGURE 6. Effect of hypertonic arabinose on the permeability of cultured brain microvessel endothelial cells in monolayer. Transcellular movement of the protein tracer horseradish peroxidase (HRP) was monitored by appearance of its reaction product. (A) control. Five minutes after exposure to HRP, the cleft between two adjacent endothelial cells contains no tracer. The HRP forms small discrete patches on the surface of the cells but does not penetrate beyond the first tight junction (arrow). The basal surface is free of HRP $(\times 82,500)$. (B) two-minute exposure of 1.6 $\mathrm{M}$ arabinose. The extracellular spaces between successive tight junctions (arrow heads) contain deposits of HRP. The basal surfaces are labeled with small amounts of the tracer ( $\times 66,000$ ). (C) Five-minute exposure to $1.6 M$ arabinose. HRP penetrates throughout the entire length of an interendothelial cleft (between arrows) and forms dense deposits on the basal surface of the cells $(\times 39,000)$. (From Dorovini-Zis et al. ${ }^{14}$ With permission of the publisher.) 
The two in vitro preparations discussed here-suspensions of isolated brain microvessels and cultures of brain capillary endothelial cells-provide a novel approach to the study of the blood-brain barrier. They should be especially helpful for investigating mechanisms important to regulation of brain capillary permeability.

\section{SUMMARY}

The endothelial cells in brain capillaries are the anatomic site of the blood-brain barrier. To learn more about the biology of these specialized cells, we developed methods to prepare suspensions of purified brain microvessels as well as primary cultures of endothelial cells in monolayer. These two preparations allow for direct investigation of the metabolism, transport properties, and receptor content of the brain capillary. We used isolated brain microvessels to study distribution of membrane carriers between the luminal and the abluminal plasma membrane of endothelial cells. We found that $\mathrm{Na}^{+} \mathrm{K}^{+}$-ATPase and the A-system amino-acid transport system are located predominantly on the abluminal surface of brain capillary endothelial cells. This distribution of transport carriers is consistent with the low permeability of potassium and small neutral amino acids in the blood-to-brain direction. It suggests, however, that both solutes can be actively transported across brain capillaries from the brain interstitial fluid to the blood. In tissue culture, the endothelial cells form continuous tight junctions with their neighbors. This results in a cellular layer impermeable to protein tracers. When exposed to hyperosmolar solutions, in an attempt to mimic the conditions that open the blood-brain barrier in vivo, we found a reversible separation of the tight junctions between contiguous endothelial cells. No indication of activation of pinocytosis was observed. In vitro systems provide a novel approach for studying the function of the blood-brain barrier and allow for observations not possible with intact animals.

\section{REFERENCES}

1. Goldstein, G. W., J. D. Wolinsky, J. Csejtey \& I. Diamond. 1975. Isolation of metabolically active capillaries from rat brain. J. Neurochem. 25: 715-717.

2. Bowman, P. D., A. L. BETz \& G. W. GoldDstein. 1982. Primary culture of microvascular endothelial cells from bovine retina: Selective growth using fibronectin-coated substrate and plasma-derived serum. In Vitro 18: 626-632.

3. Bowman, P. D., S. R. EnNis, K. E. Rarey, A. L. Betz \& G. W. Goldstein. 1983. Brain microvessel endothelial cells in tissue culture: A model for study of blood-brain barrier permeability. Ann. Neurol. 14: 396-402.

4. BetZ, A. L. \& G. W. Goldstein. 1984. Brain capillaries: Structure and function. In Handbook of Neurochemistry. A Lajtha, Ed. Vol. 7: 465-484. Plenum Press. New York.

5. BETZ, A. L. \& G. W. GoldSTEIN. 1986. Specialized properties and solute transport in brain capillaries. In Annu. Rev. Physiol. 48: 241-250.

6. Spatz, M. \& B. B. Mrsulja. 1982. Progress in cerebral microvascular studies related to the function of the blood-brain barrier. Adv. Cell. Neurobiol. 3: 311-337.

7. Shivers, R. R., A. L. Betz \& G. W. Goldstein. 1984. Isolated rat brain capillaries possess intact, structurally complex interendothelial tight junctions; freeze-fracture verification of tight junction integrity. Brain Res. 324: 313-322. 
8. Claude, P. \& D. A. Goodenough. 1973. Fracture faces of zonulae occludentes from "tight" and "leaky" epithelia. J. Cell Biol. 58: 390-400.

9. CRONE, C. \& S. P. OLESEN. 1982. Electrical resistance of brain microvascular endothelium. Brain Res. 241: 49-55.

10. Betz, A. L., J. A. FirTh \& G. W. Goldstein. 1980. Polarity of the blood-brain barrier: Distribution of enzymes between the luminal and antiluminal membrane of brain capillary endothelial cells. Brain Res. 192: 17-28.

11. BeTZ, A. L. \& G. W. GolDSTEIN. 1978. Polarity of the blood-brain barrier: Neutral aminoacid transport into isolated brain capillaries. Science. 202: 225-227.

12. BETZ, A. L. 1983. Sodium transport from blood to brain: Inhibition by furosemide and amiloride. J. Neurochem. 41: 1001-1158.

13. HARIK, S. I. 1984. Neurotransmitter receptors in cerebral microvessels. In Neurotransmitters and the Cerebral Circulation. E. T. MacKenzie, J. Seylaz \& A. Bes, Eds. 2: 1-9. Raven Press. New York.

14. Dorovini-ZIs, K., P. D. Bowman, A. L. BetZ \& G. W. Goldstein. 1984. Hyperosmotic arabinose solutions open the tight junctions between brain capillary endothelial cells in tissue culture. Brain Res. 302: 383-386.

15. Rapoport, S. E., M. HorI \& I. KLATZo. 1972. Testing of a hypothesis for osmotic opening of the blood-brain barrier. Am. J. Physiol. 223: 323-331.

16. BeCK, D. W., H. V. Vinters, M. N. HART \& P. A. Cancilla. 1984. Glial cells influence polarity of the blood-brain barrier. J. Neuropathol. Exp. Neurol. 43: 219-224.

17. GoldSTEIN, G. W. \& A. L. BETZ. 1983. Recent advances in understanding brain capillary function. Ann. Neurol. 14: 389-395.

\section{DISCUSSION}

H. Davson (London, England): Do the cells of the isolated capillaries keep their potassium? This is a fairly good index as to the integrity of the cells.

G. W. GoldSTEIN (University of Michigan, Ann Arbor, MI): It is. Their potassium concentrations are more like 20 or 30 millimolar rather than 100 millimolar. That is not true of the cultured cells, and one of the reasons for going from the isolated capillary to the cultured cell is the question of health, energy charge, and the identity of the population.

R. SPECTOR (University of Iowa, Iowa City, $I A$ ): What is the $K_{\mathrm{m}}$ that you get for glucose in these isolated capillaries from your recent preparations?

GoLDSTEIN: We did not measure $K_{\mathrm{m}}$ because of the rapidity of glucose movement. At the earliest time point we can reliably measure, 10 seconds, we're already threequarters to equilibrium. The uptake is cytochalasin sensitive, phloretin sensitive, phlorizin insensitive, and there is a great difference between the L-glucose and the D-glucose space.

J. Fenstermacher (State University of New York, Stony Brook, NY): As I understand Christian Crone's interpretations of his diffusion potential studies, most potassium seemed to go between the cells. This is different from what you are seeing in your potassium-uptake studies in isolated and cultured cells. So trying to compare Christian's numbers for potassium permeability to yours might be misleading because most of his potassium is going paracellular, that is, through the tight junction, whereas you are studying the uptake into the endothelial cell itself.

GoldSTEIN: Yes, but I think the efflux may well be different than the influx. 
Infiux may be a leak through that paracellular pathway. Efflux may also involve a saturable carrier.

M. W. B. BRADBURY (King's College, London, England): There would be a problem with that, though, in that the relative permeability for influx of potassium is between 5 and 10 times greater than sodium, which doesn't really fit with Christian Crone's observations.

C. Crone (Panum Institute, Copenhagen, Denmark): No it doesn't, and to me it's very frustrating if it really is the case that potassium gets into the brain that much faster than sodium. Our experiments performed by Dr. Hansen showed that a bolus injection of potassium into the carotid artery doesn't reflect itself at all in the brain tissue. This doesn't indicate any large potassium permeability, so I am not sure about this.

In the paper by you and Betz, you postulate the presence of amiloride-sensitive sodium channels and a furosemide-sensitive system, which is a cotransport system. Is there any other example of such two systems in parallel? I was puzzled by the fact that you have both systems; as I understand it you normally have either one or the other.

GoldSTEIN: We're puzzled as well. The amiloride-sensitive system was also interesting in that we only could see it under the artificial circumstance of a very low sodium concentration in the injectate. When sodium was $140 \mathrm{mM}$, we could not see an effect of amiloride. When we lowered the concentration to $1.4 \mathrm{mM}$ sodium, that's when you could see the inhibition by amiloride at a concentration of $10^{-7} \mathrm{mM}$. Even the hydrogen sodium antiport is amiloride sensitive but at a higher concentration, and it may well be that there is more than one class of amiloride-sensitive transporters.

CRONE: It's the presence of the cotransport together with the sodium channels.

GoLDSTEIN: Right, I understand the dilemma.

N. J. Aввотт (King's College, London, England): We have used Christian Crone's technique of putting microelectrodes into frog brain microvessels to study potentials at the barrier (see Abstract, this volume). We have detected a component of the potential due to the Na,K-ATPase, suggesting that the pump is electrogenic and shows up with this technique. The pump component is not obvious in Crone's earlier study, but it is very small, so it is quite possible that it could be missed unless it was being looked for specifically. The pump is definitely there and does appear to be abluminal. Comparing the electrical measurements with isotope measurements may not be strictly legitimate, because the isotope method looks at unidirectional flux, whereas microelectrodes measure net flux. Isotopic potassium entry may appear higher than sodium entry and may be partly transcellular; however, it would not show up in diffusion potential measurements if it was caused by potassium-potassium exchange, or if it was accompanied by an anion, and hence electroneutral.

GoLDSTEIN: Your question is, then, if the potassium is being taken up on the antiluminal side, where is it being released? Is it the futile cycle back to the interstitium, or is there going to be some coming out across the luminal membrane to compensate for the leak in through the pericellular pathway and how is that regulated?

E. M. WRIGHT (University of California, Los Angeles, CA): Do you have $800 \mathrm{ohms,}$ or $1,000 \mathrm{ohms}$ transepithelial resistance?

GOLDSTEIN: We have about a hundred or less. It's a barrier to protein and to HRP. When we use sucrose, we can see a fair-sized leak, which is much more than you would expect. It can be greatly enhanced by hyperosmotic arabinose treatment and goes up $30 \%$ to $80 \%$. By taking out some of the calcium, we can triple the leak of sucrose. The junctions are nowhere near as tight as they ought to be, but they are probably as tight as some of the systemic capillaries; they are not like the brain capillaries. We have done freeze fracture on these cells (it wasn't in this series), and 
we do see tight junctions between the endothelial cells, but the junctions are not as complicated as the one I showed you with freshly isolated capillary.

In fact, that's the reason that we're really interested in whether the coculture technique with either conditioned media or glial cells would influence the degree of the tightness to this barrier. Also, what is it that takes what probably is a generalized capillary as it invades and multiplies and vascularizes the brain and converts it into this very tight blood-brain barrier endothelium? We do have a residual of that in our primary culture. We lose that tight characteristic when we passage these cells. There are occasional contacts, but they don't have this nice endothelial look to them as they do in the primary culture. This work is at a very primitive stage. I think we have endothelial cells, they cover the dish or a disk, they look very much like endothelial cells, and they make junctions; we can see tight junctions on freeze fracture. I think they're much leakier than they should be; they are so leaky that we can't distinguish D- from L-glucose transport. My hope is that the coculture will make some difference. This system could give a lot of insight; not only would it create the membranes for study, but it may demonstrate what the glial foot process is all about.

WRIGHT: The problem, I think, is dedifferentiation, particularly with the passage of cells.

Golostein: Yes, the passaged ones are, for us, hopeless. Even the primaries are not maintaining these properties.

WRIGHT: To understand a transport barrier, I think it's premature to go this way and make conclusions on cultured cells. 